\title{
Comparison of omission training and extinction training in mentally retarded individuals
}

\author{
JEFF S. TOPPING, HELEN J. THOMPSON, and BILLY A. BARRIOS \\ Mississippi State University, Mississippi State, Mississippi 39762
}

\begin{abstract}
The present study used a within-subject design to compare the response-eliminating effectiveness of omission training (OT) and extinction training (ET) in institutionalized Down's Syndrome individuals. An interval-by-interval inspection of the data for all subjects indicated that OT and ET did not differ consistently or noticeably in their effects on responding. Similarly, using an overall suppression measure, there was no significant difference between the effects of OT and ET when all of the individuals were considered. However, when overall suppression scores were analyzed in those subjects that reached a response-elimination criterion and in those subjects that showed overall suppression in both the OT and ET conditions, it was found that significantly more overall suppression was associated with OT than with ET. Possible explanations of these results were discussed.
\end{abstract}

In the last 5 years, increasing research attention has been given to investigating the relative effectiveness of various procedures used to eliminate responses which had previously been positively reinforced. The great majority of these investigations have compared omission training (OT), which involves the presentation of a reinforcer only after a previously reinforced response has been omitted for a predetermined interval of time, and extinction training (ET), which involves the discontinuation of previously available reinforcers.

The OT procedure is best defined by defining its two temnoral parameters: (a) a response-reinforcement interval, which specifies the length of time that reinforcement is delayed following a response, and (b) a reinforcement-reinforcement interval, which specifies the time between reinforcements if no responses are emitted.

The majority of the studies comparing the effects of OT and ET have used infrahumans as subjects. Comparisons using rats have produced all possible results. Several studies have found relatively faster response elimination with OT (e.g., Aaron \& Thorne, 1975; Thorne, McDougal, \& Topping, 1976; Miller \& LeBlanc, Note 1); in other experiments, either no significant difference between OT and ET in the rate of response reduction has been demonstrated (Atnip \& Hothersall, 1975; Uhl \& Sherman, 1971) or more rapid decreases in responding with ET have been found (Uhl, 1973; Uhl \& Garcia, 1969; Uhl \& Sherman, 1971). The results of experiments using pigeons have been much more consistent. Except for two studies (Harman, 1973, Experiment II; Topping $\&$ Ford, 1975) that found comparable rates of response elimination between OT and ET, the investigations employing pigeons (Nevin, 1968; Topping \& Ford, 1974; Topping \& Larmi, 1973; Topping, Pickering, \& Jackson, 1971, 1972; Zeiler, 1971) have shown that OT

Reprint requests should be sent to Jeff S. Topping, P. O. Drawer PF, Mississippi State, Mississippi 39762. reduced responding much more rapidly than did ET.

While most of the response-elimination research has involved infrahumans, there have been some recent attempts to compare OT and ET effects using human subjects. In experiments in which college students (Johnson, McGlynn, \& Topping, 1973; Pickering \& Topping, 1974; Topping \& Crowe, 1974; Fuller \& Reese, Note 2) and elementary and special education students (Topping, Graves, \& Moss, 1975) were used as subjects, OT has been observed to decrease responding more rapidly than did ET. However, in several investigations with institutionalized individuals (McGlynn, Miller, \& Fancher, 1975; Gandy, Note 3; Thompson, Note 4), ET has either been found to be as effective as or more effective than OT in reducing responding.

The present experiment was designed to further study the effectiveness of OT and ET in the institutionalized Down's Syndrome population. The design was patterned after that of Gandy (Note 3) but differed from his in that there was an extensive modification of the appaatus employed in order to facilitate the discrimination between OT and ET. This modification involved the use of two response keys (one for each response-elimination procedure) rather than one and the addition of another pair of discriminative stimuli.

\section{METHOD}

Subjects

The subjects were 10 Down's Syndrome individuals from the Ellisville State School, Ellisville, Mississippi. Four females and six males participated and all but one were classified as having severe mental retardation. Complete descriptive data on each subject are available on request.

\section{Apparatus}

A $49.5 \times 49.5 \mathrm{~cm}$ vertical display panel with an attached $47.5 \times 47.5 \mathrm{~cm}$ horizontal platform was placed on a table in an experimental room. Two standard telegraph keys, $7.6 \mathrm{~cm}$ apart, were centered on the horizontal platform. Green and red stimulus lights were positioned to the outside of the left- and righthand keys, respectively, and near the top of the vertical panel. 
To the left of the keys was a small reinforcer tray. Two vertically arranged Lehigh Valley counters recorded the data. Experimental events and contingencies were controlled by two experimenters, while response data and reinforcers earned were recorded manually from readings on the counters.

\section{Procedure}

The experiment consisted of three phases: (a) shaping, (b) variable ratio (VR) reinforcement training, and (c) response elimination. Experimenters were present with the subjects during each session; however, after shaping, the experimenters refrained from direct interaction with the subjects.

Shaping. Although the experimenters attempted to follow a standard procedure, shaping varied according to each subject's behavior. After being seated in front of the apparatus, each subject was told that it was possible to earn pennies in the experiment and that this possibility involved the telegraph keys. The experimenters demonstrated the procedure and then manually guided the subject through the operation. If responding was not generated, an experimenter removed the subject's hand from the key, demonstrated the procedure again, and placed the subject's hand back on the same key. In short, the procedure involved modeling and physical response guidance to induce responding. Initial responses were continuously reinforced.

VR reinforcement training. In this phase, the subjects were gradually introduced to a two-component multiple (MULT) VR 10 VR 10 schedule of nondifferential reinforcement. The green and red stimulus lights mounted near the top of the vertical panel and on the horizontal platform signaled the two components. The subject had to respond on the appropriate key (i.e., on the key with the illuminated stimulus lights) to produce reinforcers. The stimuli were randomly alternated every $2 \mathrm{~min}$, with the restriction that the same color could not occur more than twice in succession. Each color appeared eight times per session and the sequence of stimuli was changed each session.
The presentation of successive stimuli was separated by a 5 -sec period during which all lights were extinguished and responses were ineffective. For each individual subject, training continued on the MULT VR 10 VR 10 schedule until responding had stabilized (i.e., less than $20 \%$ variability in response rate with regard to each colored stimulus for three consecutive 2-min intervals) during both the green and red stimulus lights at the same time during training.

Response Elimination. During this phase, conditions in one component of the MULT schedule were switched to an OT contingency in which response-reinforcement and reinforcementreinforcement intervals of $10 \mathrm{sec}$ were used. Conditions in the other component were switched to an ET contingency in which pennies were no longer delivered. Stimulus presentations during response elimination were programmed in the same way as during VR reinforcement training. Five subjects had green associated with OT and red with ET and five others had just the opposite arrangement. Response elimination continued for 10 sessions or until the subject reduced his responding during successive 2-min presentations of the red and green stimuli to less than $10 \%$ of his stabilized VR rate for these stimuli, whichever occurred first.

\section{RESULTS}

Throughout VR reinforcement training and response elimination, the number of responses in each 30-sec interval was recorded. During the response elimination phase, each subject's response rate during OT and ET was transformed by treating it as a proportion of his stabilized response rate (i.e., the mean of the last three 2-min intervals) in the corresponding color at the end of VR reinforcement training. Thus, a transformed value

Table 1

Individual Transformed Response Rates During Response Elimination

\begin{tabular}{|c|c|c|c|c|c|c|c|c|c|c|c|c|c|}
\hline Subject & $\begin{array}{c}\text { Length of } \\
\text { Response } \\
\text { Elim } \\
\text { (Minutes) }\end{array}$ & $\begin{array}{l}\quad \text { VR } \\
\text { Response } \\
\text { Rate (per } \\
\text { minute) }\end{array}$ & $\begin{array}{l}\text { Pro- } \\
\text { cedure }\end{array}$ & 1 & 2 & 3 & 4 & 5 & 6 & 7 & 8 & 9 & 10 \\
\hline GF & $\begin{array}{l}160 \\
160\end{array}$ & $\begin{array}{l}171.50 \\
177.00\end{array}$ & $\begin{array}{l}\text { OT } \\
\text { ET }\end{array}$ & $\begin{array}{l}.76 \\
.70\end{array}$ & $\begin{array}{r}.95 \\
1.02\end{array}$ & $\begin{array}{l}1.36 \\
1.56\end{array}$ & $\begin{array}{l}1.38 \\
1.39\end{array}$ & $\begin{array}{l}1.17 \\
1.36\end{array}$ & $\begin{array}{l}1.77 \\
1.70\end{array}$ & $\begin{array}{l}1.74 \\
1.65\end{array}$ & $\begin{array}{l}1.78 \\
1.86\end{array}$ & $\begin{array}{l}1.69 \\
1.68\end{array}$ & $\begin{array}{l}1.70 \\
1.63\end{array}$ \\
\hline LG & $\begin{array}{l}160 \\
160\end{array}$ & $\begin{array}{l}200.50 \\
207.83\end{array}$ & $\begin{array}{l}\text { OT } \\
\text { ET }\end{array}$ & $\begin{array}{l}.91 \\
.95\end{array}$ & $\begin{array}{r}1.03 \\
.93\end{array}$ & $\begin{array}{l}.74 \\
.93\end{array}$ & $\begin{array}{l}.58 \\
.51\end{array}$ & $\begin{array}{l}.26 \\
.29\end{array}$ & $\begin{array}{l}.52 \\
.59\end{array}$ & $\begin{array}{l}.20 \\
.24\end{array}$ & $\begin{array}{l}.35 \\
.29\end{array}$ & $\begin{array}{l}.55 \\
.58\end{array}$ & $\begin{array}{l}.28 \\
.24\end{array}$ \\
\hline RA & $\begin{array}{l}160 \\
160\end{array}$ & $\begin{array}{l}38.33 \\
38.50\end{array}$ & $\begin{array}{l}\text { OT } \\
\text { ET }\end{array}$ & $\begin{array}{l}.63 \\
.70\end{array}$ & $\begin{array}{l}.50 \\
.98\end{array}$ & $\begin{array}{l}.86 \\
.98\end{array}$ & $\begin{array}{l}.70 \\
.86\end{array}$ & $\begin{array}{l}.59 \\
.76\end{array}$ & $\begin{array}{l}.50 \\
.79\end{array}$ & $\begin{array}{l}.44 \\
.55\end{array}$ & $\begin{array}{l}.37 \\
.54\end{array}$ & $\begin{array}{l}.25 \\
.36\end{array}$ & $\begin{array}{l}.17 \\
.28\end{array}$ \\
\hline $\mathbf{K P}$ & $\begin{array}{l}160 \\
160\end{array}$ & $\begin{array}{l}37.50 \\
42.50\end{array}$ & $\begin{array}{l}\text { OT } \\
\text { ET }\end{array}$ & $\begin{array}{l}.90 \\
.80\end{array}$ & $\begin{array}{l}.88 \\
.71\end{array}$ & $\begin{array}{l}.99 \\
.71\end{array}$ & $\begin{array}{l}.96 \\
.65\end{array}$ & $\begin{array}{r}1.07 \\
.90\end{array}$ & $\begin{array}{r}1.01 \\
.91\end{array}$ & $\begin{array}{l}1.37 \\
1.34\end{array}$ & $\begin{array}{r}1.10 \\
.92\end{array}$ & $\begin{array}{l}.75 \\
.67\end{array}$ & $\begin{array}{l}.94 \\
.63\end{array}$ \\
\hline LR & $\begin{array}{l}160 \\
160\end{array}$ & $\begin{array}{r}103.50 \\
79.00\end{array}$ & $\begin{array}{l}\text { OT } \\
\text { ET }\end{array}$ & $\begin{array}{l}.44 \\
.50\end{array}$ & $\begin{array}{l}.38 \\
.45\end{array}$ & $\begin{array}{l}.24 \\
.24\end{array}$ & $\begin{array}{l}.31 \\
.36\end{array}$ & $\begin{array}{l}.13 \\
.08\end{array}$ & $\begin{array}{l}.26 \\
.20\end{array}$ & $\begin{array}{l}.20 \\
.13\end{array}$ & $\begin{array}{l}.18 \\
.19\end{array}$ & $\begin{array}{l}.28 \\
.31\end{array}$ & $\begin{array}{l}.26 \\
.45\end{array}$ \\
\hline $\mathrm{JJ}$ & $\begin{array}{l}12 \\
12\end{array}$ & $\begin{array}{l}33.18 \\
29.50\end{array}$ & $\begin{array}{l}\text { OT } \\
\text { ET }\end{array}$ & $\begin{array}{l}2.02 \\
2.51\end{array}$ & $\begin{array}{l}1.14 \\
2.14\end{array}$ & $\begin{array}{r}1.46 \\
.64\end{array}$ & $\begin{array}{l}1.00 \\
1.42\end{array}$ & $\begin{array}{l}.21 \\
.24\end{array}$ & $\begin{array}{l}.00 \\
.00\end{array}$ & & & & \\
\hline MR & $\begin{array}{l}64 \\
64\end{array}$ & $\begin{array}{l}181.33 \\
153.67\end{array}$ & $\begin{array}{l}\text { OT } \\
\text { ET }\end{array}$ & $\begin{array}{l}.28 \\
.45\end{array}$ & $\begin{array}{l}.04 \\
.47\end{array}$ & $\begin{array}{l}.22 \\
.16\end{array}$ & $\begin{array}{l}.18 \\
.27\end{array}$ & $\begin{array}{l}.19 \\
.16\end{array}$ & $\begin{array}{l}.13 \\
.13\end{array}$ & $\begin{array}{l}.09 \\
.11\end{array}$ & $\begin{array}{l}.11 \\
.11\end{array}$ & & \\
\hline $\mathrm{CD}$ & $\begin{array}{l}6 \\
6\end{array}$ & $\begin{array}{r}97.83 \\
102.67\end{array}$ & $\begin{array}{l}\text { OT } \\
\text { ET }\end{array}$ & $\begin{array}{l}.46 \\
.71\end{array}$ & $\begin{array}{l}.16 \\
.01\end{array}$ & $\begin{array}{l}.01 \\
.01\end{array}$ & & & & & & & \\
\hline $\mathbf{A L}$ & $\begin{array}{l}20 \\
20\end{array}$ & $\begin{array}{l}171.83 \\
167.83\end{array}$ & $\begin{array}{l}\text { OT } \\
\text { ET }\end{array}$ & $\begin{array}{l}.82 \\
.97\end{array}$ & $\begin{array}{l}.84 \\
.89\end{array}$ & $\begin{array}{l}.74 \\
.92\end{array}$ & $\begin{array}{l}.44 \\
.57\end{array}$ & $\begin{array}{l}.12 \\
.47\end{array}$ & & & & & \\
\hline BR & $\begin{array}{l}10 \\
10\end{array}$ & $\begin{array}{l}204.50 \\
132.17\end{array}$ & $\begin{array}{l}\text { OT } \\
\text { ET }\end{array}$ & $\begin{array}{l}.25 \\
.64\end{array}$ & $\begin{array}{l}.00 \\
.14\end{array}$ & $\begin{array}{l}.18 \\
.15\end{array}$ & $\begin{array}{l}.17 \\
.00\end{array}$ & $\begin{array}{l}.00 \\
.06\end{array}$ & & & & & \\
\hline
\end{tabular}


Table 2

Overall Suppression Scores

\begin{tabular}{lrrccr}
\hline & \multicolumn{2}{c}{ Procedure } & & \multicolumn{2}{c}{ Procedure } \\
Subject & OT & ET & Subject & OT & ET \\
\hline GF & 1.43 & 1.45 & JJ & .97 & 1.16 \\
LG & .54 & .56 & MR & .16 & .23 \\
RA & .50 & .68 & CD & .21 & .24 \\
KP & 1.00 & .82 & AL & .59 & .77 \\
LR & .27 & .29 & BR & .12 & .18 \\
\hline
\end{tabular}

of 1.00 indicates responding at a rate equal to the stabilized VR response rate, a transformed value of 0.00 indicates cessation of responding, and a transformed value greater than 1.00 indicates an increase in response rate above the stabilized VR response rate.

Table 1 presents individual data with regard to the stabilized VR response rate in each stimulus, the length of response elimination (160 min being the maximum possible for each stimulus), and the transformed response rates during OT and ET. The duration of the response-elimination intervals presented in Table 1 was determined separately for each subject, and can be obtained for an individual by dividing that subject's total time in the response elimination phase by twice the number of intervals employed for that subject.

Inspection of the data in Table 1 indicates that there was considerable between-subject variability in stabilized VR response rates, length of the responseclimination phase, and transformed response rates during response elimination. For example, subjects produced VR response rates ranging from about 30 to $200 / \mathrm{min}$, and half of the subjects participated for the maximum possible time of $320 \mathrm{~min}$ in the response elimination phase, while others were exposed to OT and ET for just 12-24 min. Also during response elimination, two subjects tended to increase their response rates relative to their VR response rates, another responded near his VR response rate, two individuals decreased their responding almost immediately to a near-zero level, and still others exhibited more gradual decreases in responding. Most important, however, was the lack of any consistent difference between the pattern of responding observed during OT and that which occurred during ET.

Since an interval-by-interval inspection of the data indicated that OT and ET did not differ noticeably in their effects on responding during the course of response elimination, the data were examined to determine if OT and ET controlled different overall levels of responding. For OT an overall suppression score was calculated for each subject by simply averaging each subject's transformed response rates during OT, and a similar procedure was employed to obtain an overall suppression score for ET for each subject. These individual overall suppression scores are presented in Table 2.

The results in Table 2 were analyzed via four correlated $t$ tests. The four tests differed in terms of the subjects included in the computations. Using all subjects the analysis yielded no significant differences between the overall suppression scores associated with OT and ET, and a similar result was obtained when just those individuals that did not reach the response-elimination criterion (i.e., the first five subjects in Table 2) were employed. When the t test was used on the data for the subjects that did reach the response-elimination criterion (i.e., the last five individuals in Table 2), the results indicated that a significantly greater amount of overall suppression occurred during OT than in ET, $[\mathrm{t}(4)=3.21, \mathrm{p}<.05]$. Similarly, when the data for subjects that showed overall suppression scores less than 1.00 in both OT and ET were analyzed, the findings again revealed that OT produced significantly more overall suppression than did ET, $[\mathrm{t}(6)=2.99, \mathrm{p}<.05]$.

\section{DISCUSSION}

As noted earlier, consideration of the data for all subjects during the course of response elimination indicated the lack of any consistent difference in the relative effectiveness with which $\mathrm{OT}$ and ET eliminated responding.

One explanation of the similar effects of OT and ET in the present experiment involves the observation that nearly all subjects exhibited response patterns during ET which were very similar to response patterns initiated in OT. That is, there seemed to be considerable transfer from the effects of OT to ET. To be more specific, once subjects started pausing long enough to get reinforced during OT, they then tended to exhibit pausing behavior in ET. It is interesting that the marked and consistent pausing behavior which occurred in most subjects was always initiated and evident during OT before it was in ET. It is believed that the similar pausing behaviors observed in OT and ET were a factor in the lack of a reliably obtained difference between the efficacy of OT and ET. Along with the pausing behavior, subjects occasionally emitted brief bursts of responses in both OT and ET. These bursts occurred more frequently during ET than they did in OT, and did not consistently follow presentations of the reinforcer during OT.

Because of the apparent transfer of effects from OT to ET, the present use of a within-subject design to compare the effects of OT and ET would appear, in retrospect, to be inappropriate. However, the inappropriateness of the within-subject design employed here is questionable considering the results of Thompson's (Note 4) study. Using individuals classified as severely retarded (as were 9 of the 10 subjects in the present study), he compared the effects of OT, ET, and gradual OT via a between-groups design. His results indicated that the three techniques did not have differential effects on responding. Since OT and ET have been shown to have similar effects in within-subject and between-groups designs with severely retarded individuals, the type of design used in such comparisons does not seem to account for the results obtained to date.

Other explanations exist to account for the present findings. For example, it is possible that the methodology employed was inadequate to reveal any differential effects that OT and ET might have in severely retarded subjects. Of course, it is also quite possible that OT and ET are simply equally effective response-elimination techniques in the subject population used here.

A word is in order regarding the overall suppression scores presented in Table 2 and the two significant results which were based on this dependent measure. The overall suppression score is certainly a gross measure of responding during response elimination, and the results of any statistical analyses using this measure should be interpreted with caution. The finding that most subjects had a lower overall suppression score associated 
with OT than they did with ET might have been due to the previously discussed observation that consistent pausing behavior was exhibited during OT before it was in ET and that brief bursts of responding occurred more frequently in ET than they did in OT.

\section{REFERENCE NOTES}

1. Miller. D. N.. \& LeBlanc, J. M. Response decrement and resumption: $A$ comparison of responding during and after differential reinforcement of other behavior. Paper presented at the meeting of the American Psychological Association. Honolulu. September 1972.

2. Fuller. E. \& Reese, E. P. A comparison of four procedures in suppressing human response rates during a five-component multiple schedule of reinforcement. Unpublished manuscript. Mount Holyoke College. 1974.

3. Gandy. W. Response elimination with omission training and extinction training for mentally handicapped children: $A$ withinsubject comparison. Unpublished manuscript. Mississippi State University. 1976.

4. Thompson. D. The efticiency of extinction and two types of omission training in deceleration of previously reinforced responding among moderately versus severely retarded persons with Down's Syndrome. Unpublished manuscript, Mississippi State University. 1976.

\section{REFERENCES}

Aaron. M., \& Thorne, B. M. Omission training and extinction in rats with septal damage. Physiology and Behavior, 1975 , 15. 149-154.

Atnip, G., \& Hothersall, D. Response suppression in normal and septal rats. Physiology and Behavior, 1975, 15, 417-421.

HaRman, R. E. Response elimination in concurrent and single operant situations with pigeons. Learning and Motivation, 1973. 4. $417-431$.

Johnson, D. L., MCGlynn, F. D., \& Topping, J. S. The relative efficiency of four response-elimination techniques following variable-ratio reinforcement training. The Psychological Record. 1973, 23, 203-208.

McGlynn, F. D., Miller, W. B., \& Fancher, J. Response elimination among chronic psychiatric patients: Extinction versus omission training. The Psychological Record. 1975. 25. $181-186$.
NeVIN. J. A. Differential reinforcement and stimulus control of not responding. Journal of the Experimental Analysis of Behavior, 1968, 11, 715-726.

Pickering, J. W., \& Topping, J. S. Comparison of six responseelimination techniques following VR reinforcement training in humans. Bulletin of the Psychonomic Society. 1974. 3. 264-266.

Thorne, B. M.. McDougal, Y..\& Topping. J. S. Olfactory bulb removal and response suppression in rats. Physiology and Behasior. 1976, in press.

Topping. J. S.. \& CRowe. J. T. Comparison of three responseelimination procedures following $\mathrm{FI}$ and VI reinforcement training in humans. Bulletin of the Psychonomic Society. 1974. 3. 49-51.

Topping. J. S.. \& Ford, T. W. Response elimination with DRO and extinction: A within-subject comparison. The Psychological Record. 1974, 24, 563-568.

ToppING. J. S., \& ForD, T. W. A within-subject comparison of three response-elimination procedures in pigeons. Bulletin of the Psychonomic Society, 1975, 6, 257-260.

Topping. J. S. Graves. A. J.. \& Moss, J. D. Response elimination in elementary and special education school children. The Psychological Record. 1975, 25. 567-572.

Topping. J. S. . \& LaRmi, O. K. Response elimination effectiveness of omission and two extinction training procedures. The Psychological Record, 1973, 23, 197-202.

Topping, J. S., Pickering, J. W., \& Jackson, J. A. The differential effects of omission and extinction following DRL pretraining. Psychonomic Science, 1971. 24.137-138.

Topping, J. S.. Pickering, J. W., \& Jackson, J. A. Comparison of omission and extinction following FR reinforcement training. The Psychological Record, 1972, 22. 221-224.

Uhl, C. N. Eliminating behavior with omission and extinction after varying amounts of training. Animal Learning \& Behavior. 1973. 1. 237-240.

UHi, C. N., \& G GíkCía, E. E. Comparison of omission with extinction in response elimination in rats. Journal of Comparative and Physiological Psychology, 1969, 69, 554-562.

Uhl, C. N., \& Sherman, W. O. Comparison of combinations of omission, punishment, and extinction methods in response elimination in rats. Journal of Comparative and Physiological Psychology, 1971, 74, 59-65.

ZEILER, M. D. Eliminating behavior with reinforcement. Journal of the Experimental Analysis of Behavior. 1971, 16. 401-405.

(Received for publication May 24, 1976.) 